\title{
A Novel Intervention to Increase Male Involvement in Prevention of Parent to Child HIV Transmission
}

\author{
Isichei Christian ${ }^{1, *}$, Courtney Snelling Jennifer ${ }^{2}$, Onwuezobe Caroline ${ }^{3}$, OyebodeTinuade ${ }^{4}$, \\ Mercy Isichei $^{5}$, Njab Jean ${ }^{6}$, AdeyanjuSegun ${ }^{3}$, Johnson Rotimi ${ }^{3}$ \\ ${ }^{1}$ Department of Chemical Pathology, Faculty of Medical Sciences, University of Jos/Faith Alive Foundation, Jos, Nigeria \\ ${ }^{2}$ Tearfund, Global Outreach Division, Teddington, UK \\ ${ }^{3}$ Faith Alive Foundation, Jos, Nigeria \\ ${ }^{4}$ AIDS Prevention Initiative in Nigeria (APIN), Jos, Nigeria \\ ${ }^{5}$ Department of Surgery, Faculty of Medical Sciences, Jos/Faith Alive Foundation, Jos, Nigeria \\ ${ }^{6}$ Department of Chemical Pathology, Bingham University, Jos Campus, Nigeria
}

\section{Email address:}

christian_isichei@yahoo.com (I. Christian)

\section{To cite this article:}

Isichei Christian, Courtney Snelling Jennifer, Onwuezobe Caroline, OyebodeTinuade, Mercy Isichei, Njab Jean, AdeyanjuSegun, Johnson Rotimi. A Novel Intervention to Increase Male Involvement in Prevention of Parent to Child HIV Transmission. Science Journal of Clinical Medicine. Vol. 4, No. 2, 2015, pp. 41-51. doi: 10.11648/j.sjcm.20150402.14

\begin{abstract}
Background: Prevention of Parent To Child Transmission (PPTCT) of HIV is a major intervention to stop the spread of HIV. Rates of $<2 \%$ are possible with early combination antiretroviral therapy. Tearfund African PPTCT Alliance (TAPA) supports a network of African partners in PPTCT through a church-based community outreach. To promote quality, TAPA conducts periodic programme audits to strengthen male partner involvement in PPTCT. Methods: The present audit was conducted among 11 TAPA partners in August 2011 to determine factors responsible for poor Prevention of Mother To Child Transmission (PMTCT) of HIV or PPTCT uptake in areas where churches and faith-based organizations work. Participants were all expectant mothers, male sexual partners and infants registered at these clinics. Each record was evaluated for evidence of HIV testing, results, treatment and prophylaxis against mother to child HIV transmission. Information on infant feeding patterns were also gathered. Intervention: In 2009, TAPA partners identified the need for a training toolkit to stimulate greater male partner involvement in PPTCT through antenatal clinics (ANCs) in church-based sites. The toolkit entitled "Guardians of our Children Health (GOOCH)" identified men as guardians of the health of their families and was designed to build the knowledge and skills of both parents to reduce HIV transmission to their infant. GOOCH has been successfully piloted by two organizations in Jos, Nigeria since 2008-Faith Alive Foundation (FAF) and ECWA AIDS Ministry (TEAM), as well as 14 other organizations across Africa. Lessons Learned: Male involvement in PPTCT through GOOCH increases rates of HIV testing among pregnant women (sometimes up to five times); motivates male partner involvement in PPTCT; and raises PPTCT awareness in communities. Records on men are not always kept at ANC clinics. Often there is a lack of follow up. National policies for ARV intervention are often inconsistent and change too quickly. Infant feeding patterns are mixed and not all programmes were able to obtain reliable data to assess this area of preventing transmission of HIV. Next Steps: Advocacy for improvements and scaling up of PPTCT especially with Nigeria being the lowest in Africa. Scale up GOOCH in communities where it was most effective and introduce it to communities where it is likely to have the greatest impact. Also, adopt the concept of Integrated Supportive Supervision trainings with integration of Maternal Child Health $(\mathrm{MCH})$ into all levels of health care system.
\end{abstract}

Keywords: Counselling services, HIV, Nigeria, PMTCT, PPTCT

\section{Introduction}

In 2006, the World Health Organization described the status of PMTCT service implementation as unacceptable, with an urgent need for a renewed public health approach to improve access. For PMTCT to be effective it needs to be accessible, acceptable and affordable. However research in Africa into accessibility, uptake and acceptability of PMTCT 
services has been predominately urban based and usually focusing on women who deliver in hospitals. Between 2009 and 2011, 409,000 new infections were averted among children. Successfully preventing HIV transmission from mothers to their children requires multiple interventions not only during pregnancy, labour and breastfeeding, but among all women and girls.

PPTCT also commonly referred to as PMTCT, is a major intervention to stop the spread of HIV. Tearfund is a United Kingdom-based Christian non-profit organization that is contributing to a global effort to eliminate transmission of HIV from the infected mother to the child by 2015. Most children living with HIV acquire the infection through transmission from their mothers who may be infected by their partners/spouses during pregnancy and lactation - hence the focus on Prevention of Parent To Child transmission. In the absence of an effective intervention, the risk of PPTCT is $20-45 \%$ (WHO 2010). This transmission rate can be reduced to below 5\% with adequate detection and intervention.

PPTCT is achieved by early diagnosis and treatment of HIV among men and women, better antenatal and delivery care, and appropriate infant feeding. The provision of antiretroviral (ARV) drugs, counseling and psychological support to help mothers and fathers safeguard their infants against the virus are key components of PPTCT.

Tearfund's approach to PPTCT is church-based and emphasizes the importance of male involvement. It is promoted through the Tearfund African PPTCT Alliance (TAPA) - a network of African partners working in the area of PPTCT through church-based community outreach. The local church and faith-based organizations can often reach into rural and marginalized communities that government programmes and other development agencies are less likely to access. A key asset is a highly committed network of staff and volunteers that may provide inexpensive or free expertise for counselling, medical care and follow up for PPTCT.

In Nigeria, men are reticent to be tested for HIV and to take part in caring for the health of their partners and children. Childcare is traditionally seen as the woman's job. Encouraging men to get HIV testing and treatment, learn good parenting skills and offer support to family members affected by HIV has been a novel church-based approach to PPTCT in recent years. Identifying the importance of male involvement in PPTCT led to the writing and production of the Guardians of Our Children's Health (GOOCH) training kit in 2009. GOOCH aims to promote a sense of identity and vision for men as guardians of the health of their families and to build the knowledge and skills of both parents in order to reduce the risk of HIV transmission to their children.

\subsection{Study Design}

This study involved an audit among 11 TAPA organizational partners in August 2011 after implementation of a novel PPTCT intervention developed by Tearfund entitled "Guardians of our Children Health (GooCH)". 841 HIV positive pregnant mothers, 2305 Male sexual partners and 721 infants were involved in the cross sectional study.

\subsection{Setting and Participants}

The following TAPA partners were involved;

1. Democratic Republic of Congo - Centre Médical Evangélique Stop SIDA (CME)

2. Democratic Republic of Congo - Heal Africa

3. Democratic Republic of Congo - Province de l'Eglise Anglicane du Congo (PEAC)

4. Malawi- Evangelical Association of Malawi (EAM)

5. Malawi - Livingstonia Synod AIDS Programme (LISAP)

6. Nigeria - The Evangelical Church of West Africa AIDS Ministry (TEAM)

7. Nigeria - Faith Alive Foundation(FAF)

8. South Sudan - Tearfund's Disaster Management Team (DMT) in Kodok

9. Uganda - AIDS Care, Education and Training (ACET)

10. Cote d'Ivoire - Groupe Bibliques des Hôpitaux de Cote d'Ivoire (GBH-CI)

11.Zambia - Evangelical Fellowship of Zambia (EFZ)

All 841 HIV positive pregnant mothers, Male sexual partners 2305 and 721 infants were involved.

\subsection{Data Collection}

Each organization collected data (i.e. demographic, etc) from Antenatal clinics where the organization works and also gave a narrative description of factors Based on structured interviews by trained staff involved on factors that helped or hindered the successful implementation of PPTCT intervention. The analyses included all expectant mothers, male partners and infants who had registered at these clinics. Each record was evaluated for evidence of HIV testing (mothers, male partners, and infants), CD4 T-cell results, ARV treatment and prophylaxis with Highly Active AntiRetroviral Therapy (HAART) against mother to child transmission.

Information on infant feeding patterns were also gathered by interviewing mothers at Antenatal clinics in order to assess the impact this may have in mother to child transmission.

\subsection{Intervention}

The work is based on the pilot work carried out by Tearfund from 2008 to 2010 and finalized in 2011 in which 14 organizations across Africa worked in an effort to determine factors that are responsible for poor PMTCT intervention uptake in Africa, especially in areas where churches and faithbased organizations work. Through medical audits carried out in by the seven partners in Africa, it became apparent that one of the mitigating factors is lack of support by male partners of pregnant women in ANCs. Lack of involvement of men puts women at higher risk of HIV infection during pregnancy, thus increasing the risk of vertical transmission during birth. One reason for this is that if an HIV negative pregnant woman becomes infected during pregnancy, the resulting high viral load during the acute infection phase results in a high chance of transmitting the virus to the child. 
To specifically address the challenge of male involvement the Tearfund developed a toolkit titled "Guardians of our Children Health (GOOCH)". Through workshops and collaboration, TAPA partners identified the need to develop training/facilitation materials which involved the male partner more in PPTCT. This led to the writing and production of the GOOCH toolkit in 2009. GOOCH aims to promote a sense of identity and vision for men as guardians of the health of their families and to build the knowledge and skills of both parents in order to reduce the risk of HIV transmission to their child. It does this by clarifying how HIV can be transmitted from Parent to Child and addressing the challenges of stigma and discrimination. The package is designed to be used in interactive group sessions, primarily within a Christian context. It can also be used effectively within wider community groups. Two of the organizations that have piloted the use of this toolkit in Nigeria since 2008 are Faith Alive Foundation (FAF) and The ECWA AIDS Ministry (TEAM) both in Jos, Nigeria.

\section{Results}

The following key findings were highlighted through the audit process

- Male involvement in PPTCT of HIV through GOOCH increases rate of HIV testing among pregnant women five times.

- GOOCH training motivates male partner involvement including creating PPTCT awareness in churches, mosques and communities

- Poor record documentation on men

- Lack of follow up in the programmes

- National policies for ARV intervention are often inconsistent and change quickly.

- Infant feeding are mixed and records are poor.

The pilot has proven that churches/faith-based NGOs and communities can be mobilized and trained to identify and support pregnant women and their male partners through the whole process of counselling, HIV Testing, Treatment and Support until 6 months after birth.

- Tearfund partner rates of HIV testing among pregnant women exceeded national rates, according to the most recent UNICEF data.

- There were successes and challenges in involving male partners in PPTCT.

- Success stories of how GOOCH has been used to raise awareness of PPTCT in communities and to encourage men in particular to take actions.

- An evidence-based platform for scaling up PPTCT programmes among church-based organizations where HIV/AIDS is endemic.

New guidelines from WHO have highlighted the importance of focusing on PMTCT. This has the potential to improve child survival and maternal health, reduce motherto-child transmission rates to $5 \%$ or lower and virtually eliminate paediatric HIV infection.

The involvement of male partners to scale up PPTCT efforts has been highlighted as one of the areas where improvement is needed.

In Nigeria where women have limited power, rights, and poor economic base, almost every activity of the woman is tied to her husband. This study found that the use of the GOOCH toolkit was able to educate the community (men and women together) on the importance of ANCs and PPTCT. The male partner was involved in sensitization, mobilization and training of churches/faith-based NGOs and communities to identify and support pregnant women and their male partners through the whole process of ANC, counselling, HIV testing, ARV prophylaxis, infant feeding counselling, family planning, child care and referrals. Church and faithbased NGOs effectively implemented the GOOCH toolkit as a new approach to PPTCT in 11 TAPA sites.

Sensitization, mobilization and training of churches and communities to identify and support pregnant women and their male partners through the whole process of counselling, HIV testing, treatment and support is an approach to PMTCT that will yield a better result in the quest to achieving zero percent vertical transmission of HIV. This is possible because, through communities and male partners' support, greater percentage of pregnant women will be encouraged to attend ANC which in turn will provide an opportunity for them to receive HIV COUNSELING AND TESTING (HCT) on first clinic visit, deliver babies under safe delivery practices, and treatment to reduce vertical transmission and loss to-followup in PMTCT programmes. The project improved HCT among men.

\subsection{Lessons Learned}

The findings from the recent TAPA audit drew attention to various successes and challenges of Tearfund partners' PPTCT programmes and can be a useful guide to steer ongoing work. Motivating male involvement in PPTCT has been a challenge for many partners. Partners reported that men are often unwilling to be tested for HIV and tend to see pregnancy and childcare as the sole responsibility of women. Furthermore, many health clinics do not keep adequate records on male partner testing and involvement, so progress and trends in this area are difficult to track. However;

- While the involvement of male partners in PPTCT remains a challenge for most partners, successes can be identified and celebrated.

- It is useful to showcase examples of best practices with regards to motivating male partner involvement and to think creatively on how these can encourage other partners to explore new initiatives. However, the specific context of each partner programme must be considered carefully.

- The overall goal is to ensure that pregnant women and their male partners receive quality care from pregnancy to six months after birth, through interventions focusing on male partner involvement thereby reducing vertical transmission and receive community support to reduce loss to follow up in PPTCT with a long-term goal of attaining zero vertical transmission of HIV/AIDS. 


\subsection{Overview of the Data}

Table 1 shows an overview of findings for TAPA partners in 2011 including number of pregnant women, HIV prevalence, rate of CD4 testing, ART uptake, male partner testing and HIV prevalence, and infant exposure and testing rates. The rate of PPTCT prior to initiation of the intervention was not available

Table 1. Data on pregnant women, HIV prevalence, CD4 and ARV uptake, male partner testing and infant testing.

\begin{tabular}{|c|c|c|c|c|c|c|c|c|c|}
\hline & $\begin{array}{l}\text { \# of pregnant } \\
\text { women } \\
\text { registered at } \\
\text { ANC }\end{array}$ & $\begin{array}{l}\% \text { of } \\
\text { pregnant } \\
\text { women } \\
\text { tested }\end{array}$ & $\begin{array}{l}\text { HIV } \\
\text { prevalence } \\
\text { among } \\
\text { pregnant } \\
\text { women } \\
\end{array}$ & $\begin{array}{l}\% \text { of } \mathrm{HIV+} \\
\text { pregnant } \\
\text { women } \\
\text { receiving } \\
\text { CD4 count }\end{array}$ & $\begin{array}{l}\text { \% of pregnant } \\
\text { women started } \\
\text { on ART }\end{array}$ & $\begin{array}{l}\text { \% of } \\
\text { male } \\
\text { partners } \\
\text { tested }\end{array}$ & $\begin{array}{l}\text { HIV } \\
\text { prevalence } \\
\text { among male } \\
\text { partners } \\
\text { tested }\end{array}$ & $\begin{array}{l}\% \text { of } \\
\text { exposed } \\
\text { infants } \\
\text { tested by } \\
\text { PCR } \\
\end{array}$ & $\begin{array}{l}\text { \% of infants } \\
\text { tested HIV+ } \\
\text { by PCR }\end{array}$ \\
\hline $\begin{array}{l}\text { Cote d'Ivoire - } \\
\text { GBH }\end{array}$ & 528 & $95 \%$ & $5 \%$ & $100 \%$ & $24 \%$ & $4 \%$ & $26 \%$ & $15 \%$ & $9 \%$ \\
\hline DRC - CME & 4,253 & $39 \%$ & $1 \%$ & $0 \%$ & $0 \%$ & $1 \%$ & $0 \%$ & N/A & N/A \\
\hline $\begin{array}{l}\text { DRC - Heal } \\
\text { Africa }\end{array}$ & 4,865 & $23 \%$ & $6 \%$ & $16 \%$ & $9 \%$ & $1 \%$ & $20 \%$ & $0.3 \%$ & $25 \%$ \\
\hline DRC - PEAC & 699 & $45 \%$ & $5 \%$ & $93 \%$ & $93 \%$ & $17 \%$ & $4 \%$ & $1 \%$ & 0 \\
\hline Malawi - EAM & 4,953 & $97 \%$ & $8 \%$ & $100 \%$ & $66 \%$ & $3 \%$ & $15 \%$ & $4 \%$ & $7 \%$ \\
\hline Malawi - LISAP & 2,054 & $69 \%$ & $3 \%$ & $23 \%$ & $21 \%$ & $3 \%$ & $2 \%$ & $0.6 \%$ & N/A \\
\hline Nigeria - TEAM & 682 & $100 \%$ & $15 \%$ & $100 \%$ & $100 \%$ & $16 \%$ & $19 \%$ & $14 \%$ & $4 \%$ \\
\hline $\begin{array}{l}\text { Nigeria - Faith } \\
\text { Alive }\end{array}$ & 289 & $100 \%$ & $33 \%$ & $100 \%$ & $96 \%$ & $84 \%$ & $15 \%$ & $92 \%$ & $2 \%$ \\
\hline South Sudan & 731 & $25 \%$ & $1 \%$ & $0 \%$ & $0 \%$ & $0 \%$ & $0 \%$ & N/A & N/A \\
\hline Uganda - ACET & 2,133 & $99 \%$ & $5 \%$ & $61 \%$ & $32 \%$ & $16 \%$ & $8 \%$ & $2 \%$ & $8 \%$ \\
\hline Zambia - EFZ & 185 & $98 \%$ & $3 \%$ & $80 \%$ & $60 \%$ & $28 \%$ & $4 \%$ & $8 \%$ & $33 \%$ \\
\hline
\end{tabular}

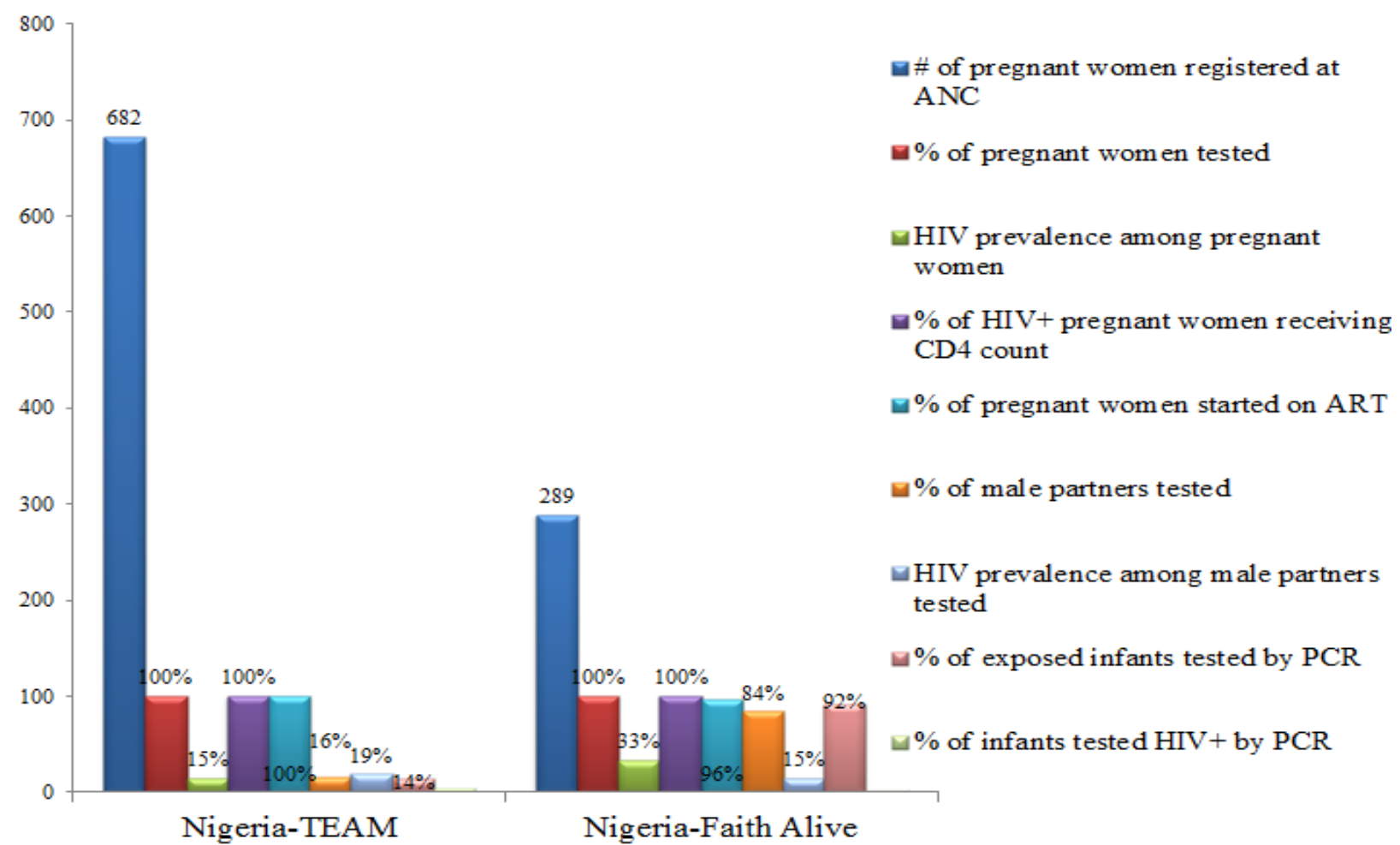

Figure 1. Description of Nigeria TEAM and Nigeria - Faith Alive sites

Table 2. Percent of pregnant women tested for HIV - partner programme rates for 2011

\begin{tabular}{lll}
\hline & TEAM $(\mathbf{N}=\mathbf{3 8 0 5}) \mathbf{N}(\mathbf{\%})$ & Faith Alive $(\mathbf{N}=\mathbf{4 7 2 1}) \mathbf{N}(\%)$ \\
\hline Pregnant Women Tested & 3655 & 4527 \\
HIV prevalence among pregnant women & $150(3.94 \%)$ & $194(4.11 \%)$ \\
\hline
\end{tabular}




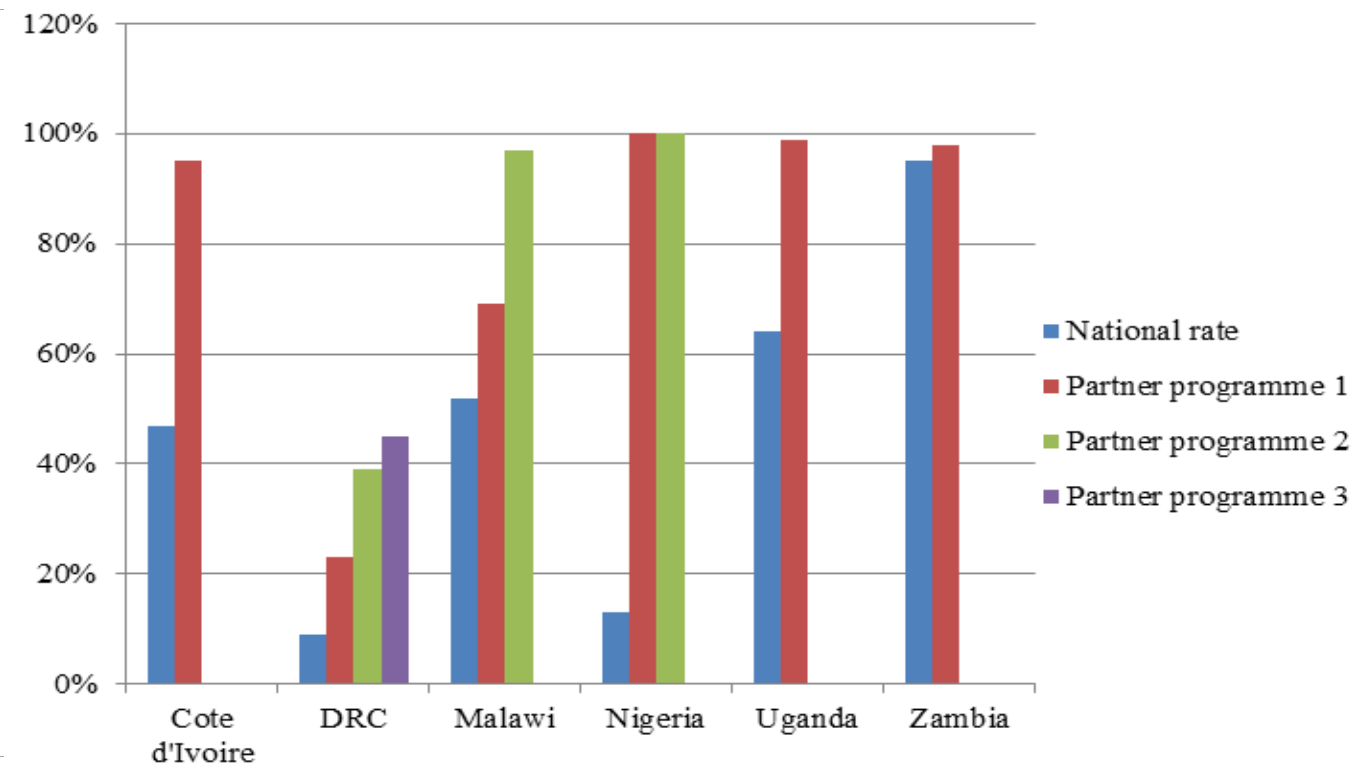

Figure 2. HIV testing rates by TAPA partner sites compared to national HIV testing rates, by country.

The level of HIV testing among pregnant women in antenatal clinics where partners work is equal to or higher than the national rates (UNICEF 2010) for 10 of the 11 partners in the 2011 audit (Figure 2)1. While many clinical, social, financial and logistical factors have contributed to these higher levels, it is useful to identify the common thread that links each of these partners - their faith basis. It may be that the overarching success of each partner in this area has been guided and strengthened by the enabling factors and qualities as faith based organizations. These qualities include an expansive reach into rural and marginalized communities, the ability to mobilize groups of women, and access to material and human resources. This supports the recent UNAIDS research that concludes that "overwhelming evidence shows that FBOs have been, and are, major providers of HIV-related services." (UNAIDS 2010)

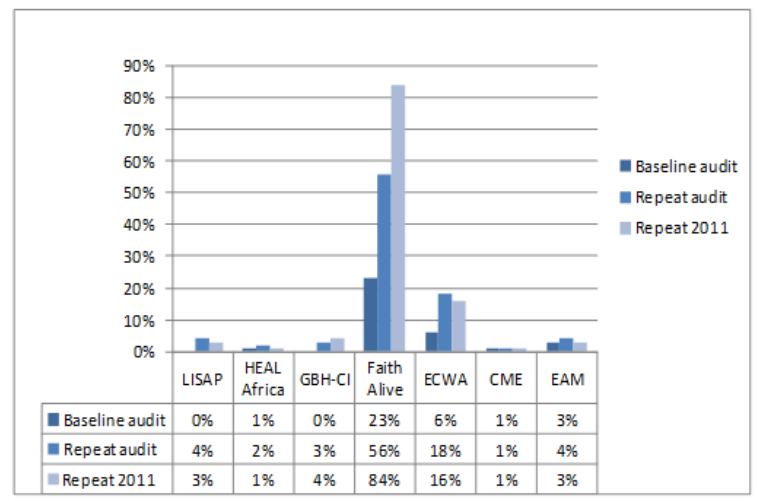

Figure 3. HIV testing rates of male partners by TAPA partner sites

\subsection{Making PPTCT Programmes Successful}

To ensure PPTCT programmes successfully prevent HIV transmission from mother-to-child, PPTCT and antenatal

1 National rates on HIV testing among pregnant women was not available for South Sudan. services must be available, efficient and accessible. Mothers must be able to access antenatal services early and be retained on PPTCT programmes from beginning to end. In reality, however, and due to a range of interacting factors, explored below, many women do not follow this essential pathway.

\section{Discussion of Implementation}

As the introduction outlines, PPTCT begins with the nonpregnant woman. By educating all women of childbearing age how to stay HIV-negative, the risk of HIV transmission from mother-to-child is significantly reduced. This is reliant not only on national HIV prevention programmes, but on the availability and accessibility of family planning services. Access to family planning is also crucial for HIV-positive women to control their pregnancies and to reduce unplanned pregnancies. Maintaining the sexual health of women both through their pregnancies and beyond is reliant on antenatal and PPTCT services reaching women who need them.

\subsection{Visiting the Clinics}

Pregnant women in low- and middle-income countries are often unable to easily access antenatal and PPTCT services. Besides caring for their children they are expected to work hard preparing food, fetching water or tending crops. Many live a long way from their nearest health facility and have little access to transport. Between 2005 and 2011, nearly a third of pregnant women, in South-East Asia, Eastern Mediterranean and African Regions, did not attend an antenatal clinic. Women that do visit an antenatal clinic often only do so once during their pregnancy. This greatly reduces the number of women that can be reached by PPTCT programmes.

To increase attendance, clinics should aim to be as accessible as possible. Improvements might include providing travel services or changing opening hours. Women 
who are HIV-positive should be encouraged to give birth at a clinic, as this reduces the risk of maternal mortality and HIV MTCT. However, this is often not possible due to the distance between home and clinics. In some clinics, waiting mothers' shelters provide accommodation for women nearing the end of their pregnancy to ensure they deliver within a healthcare setting. With the help of male participation, this exercise can be made easy, smooth and possible. The clinics should also provide integrated MCH supportive services to all.

\subsection{Access to Treatments}

As many women still deliver at home, it is important to ensure that those who test positive for HIV have access to the necessary antiretroviral drug needed for PPTCT, including treatment for the neonate/infant. Often times, the labour pains start in the absence of the man and the woman delivers in the absence of the husband. Option $\mathrm{B}+$ is the latest treatment option recommended by the WHO for PPTCT. Unlike other treatment options, Option B + recommends that all HIVpositive pregnant women are placed onto a triple antiretroviral regimen (HAART) for PPTCT, irrespective of their CD4 count, and continuing for life. This approach protects the health of the mother, whilst also reducing the risk of HIV transmission to her child and all future pregnancies. Option $\mathrm{B}+$ also provides mothers with antiretroviral treatment without waiting for laboratory results, as this wait can lead to a delay in accessing treatment or to mothers being completely lost to follow up.

Previous treatment options, such as Option A (which is no longer recommended by WHO) recommended that pregnant women, receiving treatment solely for PPTCT, should take a number of different drugs, throughout various stages of pregnancy (antenatal, delivery and postpartum). This option made PPTCT interventions complicated and difficult to implement successfully. For instance, in settings where access to treatment and clinics is difficult, mothers may fail to return for each treatment stage. Using the same standard fixed-dose combination regimen for both PPTCT and firstline treatment in adults, as recommended in Option B and $\mathrm{B}+$, enables a more efficient treatment supply-chain. It makes it easier to monitor supply levels and thus predict the amount of each drug that needs ordering.

To be fully effective, antiretroviral medication needs to reach newborn babies as well as their mothers. Infant doses are given in syrup form and are usually available only to women who give birth in clinics. Some programmes have however, succeeded in dispensing the syrup in advance, inside sealed oral syringes, so it can be given after home births especially with the involvement of Trained Birth Attendants. PPTCT programmes can increase acceptance of self-administered drugs by working with Traditional/Trained Birth Attendants, who attend the majority of home deliveries. With sufficient training, traditional midwives might also be able to provide other services such as HIV education, testing and counselling, and advice on infant feeding.

There should also be Advocacy for improvement and scaling up of PPTCT and PPTCT Support groups through sensitization, education and gatekeepers in the community like the religious leaders, with the use of GOOCH toolkit in churches, community and mosques.

\subsection{Clinic Resources}

Preventing Mother-To-Child Transmission of HIV is reliant on strong healthcare systems and infrastructure. However, in many countries there are short supplies of healthcare workers, which can adversely affect the standard of care and capacity of clinics. Moreover, an inefficient supply of PPTCT drugs or HIV testing kits and the separation of core services can make visits to health clinics prolonged or unnecessary. These negative experiences of health clinics can dissuade pregnant mothers from accessing these key services. A lack of capacity and coordination may also result in gaps in the care delivered to mothers; for example an overworked healthcare worker may fail to deliver a key PPTCT intervention, such as an initial or first HIV test.

Ultimately, the best solution is to recruit more health workers. In the shorter term, better training, greater support and motivation can improve the efficiency of existing staff. Another proven remedy is the recruitment of lay counsellors, either paid or unpaid (volunteers), to help provide counselling. With a few weeks training and ongoing supervision, lay counsellors can give a good quality service and lighten the workloads of full-time professionals.

The services that pregnant women access during their pregnancy are often situated across a number of locations. These can include: Maternal, Neonatal, Child healthcare facilities, labour and delivery, ART centres and laboratory diagnostic services; all services play a role in the PMTCT and the health of mothers. Coordinating and integrating these services can improve uptake and make the functioning of health clinics more efficient.

\subsection{Testing}

The conventional form of HIV testing in antenatal clinics is called VCT - Voluntary Counselling and Testing or more recently HIV Counselling and Testing (HCT).This is when women are offered an HIV test. An alternative model is routine testing, whereby women are told that HIV testing is a standard part of antenatal care, but they can opt out if they want to. Removing the special status that is often given to HIV testing helps to make it more acceptable. Numerous studies have found that switching from VCT/HCT to routine testing can dramatically improve uptake of testing in PPTCT programmes. For example, at one hospital in rural Uganda, the proportion of pregnant women with documented HIV status at discharge more than doubled from 39 percent to 88 percent after routine testing was introduced. When Botswana changed its testing procedure nationwide in 2004, it immediately increased testing rates from 75 percent to 90 percent. Further supporting this was a review of 44 studies carried out across 15 countries, which found that uptake of HIV testing among pregnant women was 94 percent when 
the test was opt-out; compared to 58 percent when this service was provided as opt-in.

Nevertheless, despite an increased focus on HIV MTCT in recent years, and evidence that testing uptake among pregnant women has nearly doubled in low- and middleincome countries 40 percent of pregnant women in low- and middle- income countries received an HIV test in 2012. The process of delivering HIV testing can be even more successful if the basic information given before testing is addressed to small groups instead of individuals. One-to-one counselling on personal issues can then follow as required. Importantly, the choice whether to test for HIV must remain with the mother. It is evident that in some 'opt-out' settings women do not feel that HIV testing is their choice, but perceive testing as compulsory if they wish to access antenatal care. This shows that there is a discrepancy between global targets and local realities of antenatal HIV testing.

There are huge benefits for pregnant women to receive an HIV test, yet unless a woman returns to receive her results these benefits are lost. This is why PPTCT programmes use rapid testing at a woman's first antenatal clinic visit. Unlike conventional HIV tests, which take days or even weeks, rapid tests can produce a result in as little as twenty minutes. This helps to enrol women, found to be HIV-positive, immediately into PPTCT programmes, reducing the numbers that are lost to follow-up.

PPTCT interventions can still be effective in the third trimester, during labour and even after delivery. Programmes should therefore seize every opportunity to offer testing to women of unknown HIV status. They should also consider retesting women who were previously negative, in case they have since become infected. A study of eight hundred pregnant women in Botswana showed an estimated 2 percent of pregnant women who had previously taken part in routine testing for HIV and were found to have a negative status developed HIV later in pregnancy or during postpartum.

Therefore, women who had been tested immediately after being infected with HIV ('primary' or 'acute' infection), and before HIV antibodies were produced, and those who became infected after routine testing, were missed. Using these results researchers estimated that 43 percent of mother-tochild infections in Botswana during 2007 may have been due to undetected HIV infection late in pregnancy and postpartum. By integrating HIV counselling and testing into all parts of the maternal and child health system - including family planning clinics, labour and delivery services, postpartum care and even immunisation clinics - PPTCT programmes can reach significantly more women.

\subsection{Stigma, Fear and Disclosure}

HIV-related stigma and discrimination are found in all societies and can lead to social isolation and even the support of partners, family and community. Fear of such prejudice can cause some women to refuse HIV testing, or to not return for their test results. The lack of confidentiality among healthcare workers must be addressed in order to attain public confidence in the privacy of HIV testing. Among pregnant women who do take a test and are found to be HIVpositive, a high proportion (sometimes up to 70 percent) chooses not to tell their partners. Most are afraid of violence or abandonment: in many societies it is common for men to blame their partners for being infected, even if they too have HIV. As many women are reliant on the support of their male partners, the risk of losing this, particularly financial, support can dissuade them from testing, or from disclosing their HIV status.

An HIV-positive, pregnant woman who has not disclosed her diagnosis to her partner, family or friends is generally less likely to accept preventive drugs and to practice unconventional methods of infant feeding, for fear of revealing that she is infected. PPTCT programmes should therefore seek to make disclosure less difficult for their clients, for example by running HIV/AIDS support groups or anti-stigma campaigns. They might also try to identify and assist those who wish to avoid or defer disclosure. Involving male partners in PPTCT programmes has been shown to improve the reach and success rate of PPTCT.

Tragically, in a number of countries, reports of forced abortion and sterilization of HIV-positive women, often during labour, remain. Stigma and fear of healthcare settings can cause HIV-positive women to be fearful of prenatal services, which may prevent them from attending clinic and thus from accessing PPTCT services. Moreover, pregnant women who engage in behaviours', such as sex work or drug use, are at an increased risk of HIV-infection. They may not, however, due to policies that criminalize these practices, access HIV testing services or, if they do test HIV-positive, PPTCT services, for fear that their child will be removed from their care. As UNAIDS emphasizes:

"It is not enough for services to exist: the conditions that enable women to make use of them must be in place" - UNAIDS (2012) ' Women Out Loud'

\subsection{Male Involvement}

A study conducted in Africa particularly from Kenya revealed that where women are supported and accompanied by their male partners, they are more likely to consistently visit antenatal clinics. Unlike in some regions across West Africa especially Nigeria, where caring for and support to an HIV patient is viewed as a woman's responsibility, and as liability for the man. Few men usually accompany their wives on visits to antenatal clinics for fear of being ridiculed by peers-"woman wrapper". However it has been shown that when male partners are involved, both partners can get tested for HIV, know their status, and therefore improve the baby's chances of a healthy survival. Following a strict infant feeding method is a key part of PPTCT; yet such methods are often contrary to traditional feeding methods, which may involve supplementing breast milk with porridge or other solids. Diversions from the chosen infant feeding method are less likely, however, if both parents are involved in this decision.

Furthermore, if couples are counselled and tested together 
then there is less potential for blame and recrimination. Counsellors can emphasize the man's responsibility for protecting the health of his partner and family, and can promote the use of PPTCT and other services, resulting in much higher rates of treatment uptake.

Again in Africa, Rwanda is one country that has greatly increased their focus on the participation of men in PPTCT. An estimated 81 percent of pregnant women who tested for HIV in 2010 had male partners who had tested in the last twelve months, many of whom received testing with their partner during the antenatal care process.

Moreover, in Uganda, male partner testing in antenatal care has risen from 5.9 percent to 76 percent over the last decade, as a result of peer sensitisation and the establishment of male-friendly areas in antenatal facilities. This has immense benefits; one Kenyan study found that the involvement of men decreased the risk of vertical transmission by 40 percent. If other Countries across Africa and the world at large, will imbibe the practice of male involvement in preventing PPTCT as in Kenya, Uganda and other Countries with such track records, it will go a long way in putting a check on the menace of HIV transmission. However, there are issues that need to be addressed.

Occasionally, women leave the PPTCT process completely when asked to bring their partner to a clinic due to a fear of domestic repercussions if they are found to be positive. It has even been found that for some women, involving their partner in HIV testing during the antenatal period has put them in danger of domestic violence, particularly when the woman is found to be positive and the man negative.

For male involvement to work effectively antenatal clinics have to be accessible to men and messaging around HIV testing during pregnancy needs to be equally targeted at men. Possible ways to increase male participation include hand delivered invitations and routine testing for men who accompany their partners as done at Faith Alive Foundation Hospital and PMTCT Center. Unfortunately, it is usually far from easy to persuade men to attend what they regard as women's clinics dealing with women's issues.

A case study on male involvement in PPTCT from Nigeria

Faith Alive Foundation and Hospital, based in Jos, Nigeria has worked proactively to involve men in their antenatal services. When a woman attends the clinic, she is given an invitation card for her partner to come to the hospital for a routine discussion. There is no mention of HIV testing on the card. The hospital staff appreciate that many men will be taking time off of work to attend the clinic so they are flexible in scheduling visits for men and give priority treatment to men at the clinic. Women with their spouses are given immediate attention and seen first at ANCs.

Men are invited to come for individual sessions, routine group discussions with other men, or mixed group discussions with men and women, depending on what is most appropriate. Tea or breakfast is done collectively during the visit. Group discussions begin with a welcome and appreciation for coming, along with an explanation of the importance of the father's (parent's) role in antenatal care.
The nurse then teaches about childcare for partners throughout the pregnancy. In mixed groups, the nurse asks for a male volunteer to demonstrate his knowledge of how to bath a baby or how to change a diaper. This is a great source of laughter and entertainment for the group and allows participants to be involved in a fun and playful way. The sessions end with teaching about HIV and the importance of testing for PPTCT. Men are offered HIV tests immediately without needing to make a separate appointment. ARVs are ensured to those who need them.

Men proudly wear the T-shirts labeled 'Caring Dad' or 'Loving Dad' that they are given when they attend the clinic as incentive/gift. These do not bear any mention of HIV or the hospital. This encourages men to follow through with their responsibilities as fathers and to tell other men about what they have learned in the group discussions. There is currently a PPTCT support group in addition to the HIV/AIDS support group that meets weekly of both positive and negative clients as we believe negative clients are positive at heart, thus affected one way or the other.

Statements by male focused discussants such as "Men are treated like kings here, unlike other hospitals where it's not the culture for men to come to antenatal clinics" are frequently made and even pasted on walls. Despite the challenges of limited time and resources, staff and volunteers are dedicated to visiting men at home where necessary; raising awareness in churches, mosques and other places of public gathering; and taking every opportunity to speak about PPTCT with patients and in the community. Men are encouraged and given confidence to come back. For example, a common belief in Africa is that a pregnant woman cannot have sex. When men learn from hospital staff that this is not true and that there is no danger in having sexual relations with their pregnant partners, men feel like the hospital staff are "on our side".

Faith Alive also has five satellite rural clinics that have similar practices of reaching out to men in the community for PPTCT.

\subsection{Issues}

Often men are presented as an obstacle in PPTCT. Focus of health services has been on women and children hence failure to target men in programmes. This creates a gap in interventions since men can significantly influence their partner's reproductive health decisions and use of health resources. Overlooked is the potential of men to provide valuable support to HIV infected women as they attempt to prevent HIV transmission to their children. Participation of HIV infected women in PPTCT is simplified when male partners know their role in prevention and are unwilling to commit the necessary.

\subsection{Drug Effectiveness and Adherence}

The treatment option used by PPTCT programmes varies between countries and is determined at a government level. Some treatment options are more effective than others, 
however, which option is recommended in national guidelines, is largely associated with the level of available resources. Updating national guidelines to adopt the latest recommended treatment regimen, currently Option $\mathrm{B}+$, involves purchasing more expensive drugs and adapting current PPTCT programmes to distribute them; including further staff training and increasing capacity. This is a major factor that deters low-income countries from distributing the most effective, available drug treatment regimens for PPTCT. Until 2006, the most common treatment regimen used to prevent mother-to-child transmission was single-dose Nevirapine. A straightforward regimen where both the mother and the child receive a single-dose of Nevirapine each.

Overtime, however, after greater research and investment into treatments for the prevention of mother-to-child transmission, this treatment option was replaced by a more complex, yet safer and more effective treatment approach Option A (no longer recommended). The latest guidelines, released in 2013 recommends countries adopt Option $\mathrm{B}+$, and in cases where this option is unfeasible Option B.

Unlike Option A and single-dose nevirapine, the latter of which the WHO now recommends be phased out of PPTCT programmes, Option $\mathrm{B}$ and $\mathrm{B}+$ are not only more effective at preventing MTCT and less likely to lead to future drug resistance, but are also easier for health systems to implement and for patients to adhere to. This is down to the standard triple-antiretroviral drug regimen that is used for all pregnant women, irrespective of their CD4 count. The treatment is available as a single-pill fixed-dose combination, made up of a first line regimen of Tenofovir (TDF), Lamivudine (3TC), and Efavirenz (EFV).The teratogenicity of EFV not withstanding as not adequately proven but still used with caution.

Whilst Option B and $\mathrm{B}+$ are more effective, and as a result of the one-pill approach easier to adhere to, some challenges remain surrounding these treatment options; for example research to monitor the safety of Efavirenz in early pregnancy, and the difficulty ensuring good adherence to treatment when placing women on treatment for life; many may not have any symptoms of HIV, and yet may experience treatment side-effects.

\subsection{Keeping Mothers Healthy}

Keeping mothers healthy in any home or community entails the active involvement of male partners. This cannot be done with the male partners in isolation. The survival of children is reliant not only on mothers receiving treatment for PPTCT, but also on mothers receiving treatment for their own health. This has been shown in studies that found the risk of death increased among children whose mother had died, irrespective of whether or not the child was infected with HIV. Yet, despite longstanding recommendations that all pregnant women with a CD4 count of less than 350 cells $/ \mathrm{m} 3$ should begin life-long antiretroviral treatment and, more recently, evidence of the numerous benefits of placing all pregnant mothers on antiretroviral treatment for life, irrespective of CD4 count, more than two thirds of pregnant women eligible to receive treatment remain without it.

The goal of "Eliminating new HIV infections among children by 2015 and keeping their mothers alive" was launched by UNAIDS in 2011. Achieving the second half of this goal "keeping their mothers alive" relies on overcoming many of the barriers that also make implementing PPTCT services a challenge; fear and stigma of testing, difficulty accessing healthcare services, a need for integrated services particularly PPTCT and adult HIV treatment services. In addition to this, are difficulties expanding access to antiretroviral treatment to universal levels, such as, political commitment, lack of infrastructure and availability of funding. Also important, however, is the development of community support networks that provide care and support to women living with HIV.

\subsection{Feasibility of Replacement Feeding}

In July 2013, the World Health Organization (WHO) issued new HIV and AIDS guidelines on treatment for PPTCT /PMTCT and on HIV and breastfeeding - intended primarily for use in low-and middle-income countries, or resource-poor settings. The treatment and infant-feeding 2013 guidelines brought clarity around treatment recommendations, leaning clearly towards placing pregnant women with HIV on treatment for life.

2013 guidelines recommend that countries follow option $\mathrm{B}+$ and in countries where this is not feasible, option B. Option A (2006 guidelines) is now only cited as a last resort.

\subsubsection{Option B+}

Provide all HIV-positive pregnant or breastfeeding women with a course of antiretroviral drugs to prevent mother-tochild transmission. A triple-drug antiretroviral regimen should be taken throughout pregnancy, delivery and breastfeeding - continuing for life, regardless of CD4 count or clinical stage.

\subsubsection{Option B}

Provide all HIV-positive pregnant or breastfeeding women with a course of antiretroviral drugs to prevent mother-tochild transmission. A triple-drug antiretroviral regimen should be taken throughout pregnancy and delivery.

If the mother is breastfeeding, she should also continue to take the triple-drug antiretroviral regimen until 1 week after breastfeeding has finished.

Pregnant women who are eligible to receive antiretroviral treatment for their own health, based on their CD4 count or clinical stage, should continue taking HIV treatment for life. Eligibility is determined at a country level. WHO recommends women with a CD4 count of $\leq 500$ cells $/ \mathrm{mm} 3$ (or clinic stage 3 or 4 ) should continue taking antiretroviral treatment for life. This course of medication should be permanent and taken every day in order to postpone the development of HIV into AIDS.

Because HIV can be transmitted through breast milk, a mother's method of infant feeding has a strong influence on 
the likelihood that her baby will become infected. The only certain way to avoid transmission is to abstain from breastfeeding and provide replacement foods instead but this is not possible for a woman living in an area with unsafe water or inconsistent formula milk. In this situation, women should be recommended to exclusively breastfeed alongside taking an extended drug regimen.

Replacement feeding is not feasible and safe unless mothers have access to a reliable supply of safe water and fuel, as well as the ingredients for the food itself, and even then it can be time-consuming and expensive. It may seem obvious that PPTCT programmes should assist HIV-positive mothers by offering free supplies of infant formula. However, there are some drawbacks to this approach. The most significant worry is that by distributing formula, clinics may inadvertently encourage mothers to give up breastfeeding, even if they don't have HIV. In addition, mothers who have the resources to practice safe replacement feeding are the least likely to need free formula. In situations where free infant formula has been provided, supplies have been reported to be stopped, leaving many HIV-positive women with a difficult dilemma. Therefore, some people argue that supplying free formula is not an effective use of money.

\section{Conclusion}

In recent years, efforts to widen access to antiretroviral treatment have caught the attention of politicians, nongovernmental organizations and the global media. Apart from some large donors and organizations that worked closely with national governments to improve access to PPTCT services, PPTCT and the health of mothers remained largely out of the spotlight until 2011. With this renewed commitment, it seems feasible that increasing numbers of countries will add their names to the already growing list of low-and middle-income countries reaching the $80 \%$ coverage target of antiretrovirals for PPTCT.

Swift progress will depend on strong leadership from national governments, and on the committed support of foreign donors and non-governmental organizations. It will also require sustained advocacy from campaigners and the media. The programmes that are provided need to ensure that they are reaching as many women as possible. As this article has shown, this means addressing not just practical issues, but also social, cultural and personal factors. People's attitudes towards HIV are central to the success or failure of PPTCT

UNAIDS Executive Director Michel Sidibé, during a visit to a Millennium Villages Projects (MVP) in Kenya, emphasized that reducing mother-to-child transmission is an achievable goal.

"We have seen that it is possible to virtually eliminate infant HIV infections in high-income countries through HIV testing of pregnant women, contraception, and the use of antiretroviral drugs during and after delivery...Now we must apply the knowledge and tools to create an AIDSfree generation in Africa and the rest of the world.

\section{Recommendations}

- There is need for advocacy for the improvements and scaling up of PPTCT programmes especially with Nigeria being the lowest on the Africa continent.

- $\quad$ Scaling up the use of GOOCH in communities where it has been most effective and for introducing it to communities where it is likely to have the greatest impact.

- Adopting the concept of Integrated Supportive Supervision trainings with integration of $\mathrm{MCH}$ into all levels of health care system.

- Continuous sensitisation and advocacy for the male involvement in preventing parent to child transmission of HIV

\section{Acknowledgement}

Appreciations to Engr. Adebayo Bankole Data Manager/Monitoring \& Evaluation/Strategic Information Officer Faith Alive Foundation Nigeria, who helped in typing/arranging this manuscript .Also, our appreciations to Dr. Hillary Lum of Aurora Colorado,USA for guiding the preparations of this manuscript.Lastly to Tearfund,UK for funding this project.

\section{Note}

First presented as "Prevention of Parents To Child Transmission of HIV-Relevance of Male Involvement" Book of Abstracts P66-67, APIN Scientific Conference, Abuja $22^{\text {nd }}-23^{\text {rd }}$ October 2013(Theme; Integrating Research into services delivery; the gains; challenges and opportunities)

\section{References}

[1] WHO (2012, April) 'Programmatic update: Use of antiretroviral drugs for treating pregnant women and preventing HIV infection in infants', Sunday, 1 April, 2012

[2] WHO (2010) 'Guidelines on HIV and Infant Feeding 2010', Geneva; Friday, 1 January, 2010.

[3] WHO (2010) 'Antiretroviral drugs for treating pregnant women and preventing HIV infection in infants: Towards Universal Access', Geneva; Friday, 1 January, 2010

[4] WHO (2013, June) 'Consolidated guidelines on the use of antiretroviral drugs for treating and preventing HIV infection: Recommendations for a public health approach', Sunday, 30 June, 2013.

[5] UNAIDS (2012) ' World AIDS Day Report - Results'.

[6] Stringer, EM et. al (2012, 21st July) ' Coverage of nevirapinebased services to prevent mother-to-child HIV transmission in 4 African countries' JAMA 304(3).

[7] UNAIDS (2012) ' World AIDS Day Report - Results'.

[8] WHO (2012) ' World Health Statistics: 2012'. 
[9] WHO (2012, April) 'Programmatic update: Use of antiretroviral drugs for treating pregnant women and preventing HIV infection in infants"

[10] Christian Isichei' et al (2015).HIV prevalence and associated risk factors among rural pregnant women in North Central Nigeria. American Journal of Health Research;3(1):18-23

[11] WHO (2012, April) 'Programmatic update: Use of antiretroviral drugs for treating pregnant women and preventing HIV infection in infants'.

[12] Temmerman M. et al, " Mother-to-child HIV transmission in resource poor settings: how to improve coverage?", AIDS 17(8), 23 May 2003.

[13] Bulterys M. et al (26 January 2002), "Role of traditional birth attendants in preventing perinatal transmission of HIV", BMJ 324(7331).

[14] Lum H, Isichei $\mathrm{C}$ et al (2007). Expansion of HIV-1 Screening and Anti-Retroviral Treatment Programs in a Resource-Poor Setting: Results from a Faith-Based Organization in Jos, Plateau State, Nigeria. African Health Sciences, 7(2):88-95.

[15] UNICEF (2008, July) ' Guidance on ensuring effective supply chain planning for commodities needed for implementation and scale up of services for the prevention of mother to child transmission PPTCT of HIV infection'

[16] UNICEF (2008, July) ' Guidance on ensuring effective supply chain planning for commodities needed for implementation and scale up of services for the prevention of mother to child transmission (PPTCT) of HIV infection'.

[17] WHO (2013, June) ' Global update on HIV treatment 2013 : Results, Impact and Opportunities'.

[18] UNICEF (2008, December) ' Children and AIDS: Third stocktaking report, 2008'.
[19] WHO (2013, June) ' Global update on HIV treatment 2013: Results, Impact and Opportunities'.

[20] Isichei CO, Zelalem Temesgen (2009) ed. HIV Counselling. In Fundamentals of Global HIV Medicine. American Academy of HIV Med.; Chapter 6: PP 61-64

[21] Wilfert C. (13 August 2006), ' Site Specific Factors Influencing Access to PPTCT Services, Trends with Time, and Suggestions for Improvement', XVI International AIDS Conference.

[22] WHO (2011) ' Towards the elimination of mother-to-child transmission of HIV: Report of a WHO technical consultation (9-11 November 2010, Switzerland)'.

[23] Smart T. (14 July 2006), "Getting the most prevention and care out of programmes for the prevention of mother-to-child transmission", HIV \& AIDS Treatment in Practice \#70.

[24] Medley A. et al (April 2004), " Rates, barriers and outcomes of HIV serostatus disclosure among women in developing countries: implications for prevention of mother-to-child transmission programmes", Bulletin of the World Health Organization 82(4).

[25] UNAIDS (2012) 'Global Report: UNAIDS Report on the Global AIDS Epidemic 2012'.

[26] WHO/UNAIDS/UNICEF (2011) ,' Global HIV/AIDS Response: Epidemic update and health sector progress towards Universal Access 2011'.

[27] PlusNews (2012, January 16th) 'KENYA: The downside of male involvement in PPTCT '.

[28] Smart T. and Sheriff L. (14 July 2006), " Getting the most prevention and care out of programmes for the prevention of mother-to-child transmission", HATIP 